\title{
Effects of the financial crisis and Troika austerity measures on health and health care access in Portugal
}

\author{
Helena Legido-Quigley ${ }^{\mathrm{a}, \mathrm{h}, *, 1}$, Marina Karanikolos ${ }^{\mathrm{b}, 1}$, Sonia Hernandez-Plaza ${ }^{\mathrm{c}, \mathrm{d}}$, \\ Cláudia de Freitas ${ }^{\mathrm{d}, \mathrm{e}}$, Luís Bernardo ${ }^{\mathrm{f}}$, Beatriz Padilla ${ }^{\mathrm{g}}$, Rita Sá Machado ${ }^{\mathrm{h}}$, \\ Karla Diaz-Ordaz ${ }^{\mathrm{h}}$, David Stuckler ${ }^{\mathrm{i}}$, Martin McKee $^{\mathrm{h}}$ \\ a Saw Swee Hock School of Public Health, National University of Singapore, Singapore \\ b European Observatory on Health Systems and Policies, London, United Kingdom \\ c Faculty of Social Work, Department of Social Work and Social Services, University of Granada, Granada, Spain \\ d Centre for Research and Studies in Sociology (CIES-IUL), University Institute of Lisbon (ISCTE-IUL), Lisbon, Portugal \\ e EPIUnit - Institute of Public Health, University of Porto, Porto, Portugal \\ ${ }^{\mathrm{f}}$ Humboldt Universität zu Berlin, Department of Social Sciences, Berlin, Germany \\ g Instituto Universitário de Lisboa (ISCTE-IUL), Centro de Investigação e Estudos de Sociologia (CIES-IUL), Lisboa, Portugal \\ ${ }^{\mathrm{h}}$ London School of Hygiene and Tropical Medicine, London, United Kingdom \\ i Department of Sociology, University of Oxford, Oxford, United Kingdom
}

\section{A R T I C L E I N F O}

\section{Article history:}

Received 29 December 2015

Received in revised form 8 April 2016

Accepted 10 April 2016

\section{Keywords:}

Austerity

Economic crisis

Portugal

Access to care

Co-payments

\begin{abstract}
A B S T R A C T
Although Portugal has been deeply affected by the global financial crisis, the impact of the recession and subsequent austerity on health and to health care has attracted relatively little attention. We used several sources of data including the European Union Statistics for Income and Living Conditions (EU-SILC) which tracks unmet medical need during the recession and before and after the Troika's austerity package. Our results show that the odds of respondents reporting having an unmet medical need more than doubled between 2010 and 2012 ( $\mathrm{OR}=2.41,95 \% \mathrm{CI} 2.01-2.89)$, with the greatest impact on those in employment, followed by the unemployed, retired, and other economically inactive groups. The reasons for not seeking care involved a combination of factors, with a $68 \%$ higher odds of citing financial barriers $(\mathrm{OR}=1.68,95 \% \mathrm{CI} 1.32-2.12)$, more than twice the odds of citing waiting times and inability to take time off work or family responsibilities (OR 2.18, 95\% CI 1.20-3.98), and a large increase of reporting delaying care in the hope that the problem would resolve on its own $(\mathrm{OR}=13.98,95 \% \mathrm{CI} 6.51-30.02)$. Individual-level studies from Portugal also suggest that co-payments at primary and hospital level are having a negative effect on the most vulnerable living in disadvantaged areas, and that health care professionals have concerns about the impact of recession and subsequent austerity measures on the quality of care provided. The Portuguese government no longer needs external assistance, but these findings suggest that measures are now needed to mitigate the damage incurred by the crisis and austerity.
\end{abstract}

(c) 2016 Elsevier Ireland Ltd. All rights reserved.

\footnotetext{
* Corresponding author.

E-mail address: helena.legido-quigley@lshtm.ac.uk (H. Legido-Quigley).

1 Joint first authors.
}

\section{Introduction}

Although Portugal is one of the European countries most affected by the global financial crisis, there has been much less attention to the health consequences of the crisis and subsequent austerity measures compared to countries such 
as Greece, Spain and Ireland. Portugal's recession started in 2008. Despite a brief recovery in 2010, it then lost more than 6\% of GDP between 2011 and 2013 [1]. The crisis was accompanied by mounting deficits ( $9.9 \%$ of GDP in 2010) [2] and the government debt, mainly from the credit-fuelled expansion of the non-tradable sector such as retail and construction, reached 129\% of GDP in 2013 [3].

In May 2011, the Portuguese Parliament rejected austerity measures and the government requested an emergency $€ 78$ billion bailout package from international lenders - the European Central Bank, the European Commission and the International Monetary Fund - known as the Troika. The Memorandum of Understanding (MoU) with the Troika included agreement to generate substantial savings, including the health care sector [4-6].

Portugal had undergone remarkable change since the 1980s. Social conditions had improved as the creation of a welfare state tackled material deprivation and increased access to healthcare [7]. Portugal's health system is primarily funded through general taxation with a mix of public and private financing. Before the financial crisis, approximately $30 \%$ of the total expenditure was private, with nearly $25 \%$ representing out-of-pocket payments. Patient co-payments have increased over time, dominated by payments for pharmaceuticals [8]. All residents have access to health care provided by the National Health Service (NHS), and a number of reforms were implemented since the 1990 s to improve performance, especially primary care and pharmaceutical care delivery. Portugal had progressively increased expenditure on healthcare, particularly in the public sector. In 2008, when the financial crisis hit Portugal, expenditure for health care represented nearly $10 \%$ of GDP [8]. However, progress was reversed during the crisis; health expenditure declined by $5 \%$ per year in real terms in 2011 and 2012 [9], contrasting with an annual growth of $1.8 \%$ in the previous decade [10]. Per capita expenditure stood at 2514 US\$ PPP in 2013, well below the OECD average of 3453 US\$ PPP [11].

Budget cuts were achieved in several ways $[6,12,13]$. First, unit costs were forced down as the government negotiated lower prices for drugs and cut salaries of health workers. Second, more cuts were introduced in prevention, public health and research. Third, measures were implemented to reduce demand for care, mainly by increasing co-payments. Visits to primary care physicians attracted a charge of $€ 5.00$ in 2013, up from $€ 2.25$ in 2011. The corresponding increases for routine hospital visits were from $€ 4.60$ to $€ 7.75$ and for emergency visits from $€ 9.40$ to $€ 20.60$, with additional fees of up to $€ 50$ for examination and diagnosis. Increased charges have been maintained at these values through 2015, even after the termination of the MoU. The impact was, however, softened by broadening exemptions from payments to almost $56 \%$ of the population (from 4.3 million people in 2011 to 5.8 million in 2014 [14]). Exemptions are based on several criteria (family units earning less than $€ 630$ per month, the unemployed, pregnant women and children up to the age of twelve, among other groups) with the main criterion being that of economic hardship. In 2015, the Ministry of Health extended exemption from fees to youth under 18 . However, criteria for exemptions for certain conditions such as chronic
Box 1: Healthcare related austerity measures sought by the Troika.

The Memorandum of Understanding* between the Troika and the Portuguese government demanded cuts in the health care sector in order to achieve savings of $€ 550$ million in 2012, and $€ 375$ million in 2013. Measures to reform the health system were required, with particular emphasis on the following areas:

1. Financing: An increase in overall NHS co-payments (taxas moderadoras) was imposed, including (a) higher fees; (b) a substantial revision of existing exemption categories, including stricter meanstesting, in cooperation with the Ministry of Labour and Social Affairs; and (c) automatic indexation of co-payment rates with inflation.

2. Pharmaceuticals and prescriptions: A reduction in public spending on pharmaceuticals was sought, to $1.25 \%$ of the GDP in 2012, and about 1\% in 2013. This included: (a) encouraging the prescription of generic medicines and other less costly products; (b) establishing clear prescribing guidelines for physicians according to international practice; and (c) requiring electronic prescriptions for medicines and diagnostic exams covered by public reimbursement.

3. Primary care services: Strengthening of primary care services in order to further decrease unnecessary (sic) visits to specialists and emergencies, reduce costs and increase effective provision through (a) an augmented number of Family Health Units (Unidades de Saúde Familiar), based on a mix of salary and performance-related payments; and (b) a mechanism to guarantee family doctors in needed areas to induce a more even distribution of family doctors across the country.

4. Hospital services: Savings in hospital operational costs are demanded, targeting a reduction of $€ 200$ million in 2012 ( $€ 100$ in 2012, and $€ 100$ already in 2011), with an emphasis on concentration and rationalisation in state hospitals and health centres, moving some hospital outpatient services to primary care units, stricter control of working hours and activities of staff, and reducing spending on overtime compensation (at least $10 \%$ in 2012 , and another $10 \%$ in 2013).

5. Other services: additional demands were made for finalising the development of electronic medical records, and reducing costs of patient transportation by one third.

* Note: Box 1 presents the summary initial requirements of the first adjustment programme. Some of these have continued in the follow up programme, while some were taken off either as completed or due to unexplained reasons.

Source: European Commission [16].

obstructive pulmonary disease (COPD) and chronic active hepatitis were tightened [15]. Fourth, some subsidies were removed, such as tax relief on private health insurance. Box 1 sets out a more detailed description of the austerity measures sought by the Troika in 2011 . 
Table 1

Summary of 2010 and 2012 EU-SILC samples.

\begin{tabular}{|c|c|c|c|c|c|c|}
\hline \multirow[t]{2}{*}{ Variable } & \multicolumn{2}{|l|}{2010} & \multicolumn{2}{|l|}{2012} & \multirow[t]{2}{*}{ t-test } & \multirow[t]{2}{*}{$p$-value } \\
\hline & $n$ & Mean (SD) & $n$ & Mean (SD) & & \\
\hline Age (16-80 years) & 11,380 & $51.40(18.71)$ & 13,584 & $51.30(18.61)$ & 0.4384 & 0.6611 \\
\hline Sex $($ female $=0$, male $=1)$ & 11,380 & $0.46(0.50)$ & 13,584 & $0.47(0.50)$ & -0.2003 & 0.8413 \\
\hline Family status ( not married $=0$, married $=1$ ) & 11,380 & $0.60(0.49)$ & 13,584 & $0.59(0.49)$ & 0.4402 & 0.7718 \\
\hline Education $($ secondary $=0$, post-secondary $=1$ ) & 9,880 & $0.11(0.31)$ & 11,625 & $0.13(0.33)$ & -3.9169 & $<0.001$ \\
\hline
\end{tabular}

The Portuguese government was required to commit to reducing the deficit to $3 \%$ of GDP by 2013 , while "minimising impact on vulnerable groups". Yet there have been concerns that some of these measures may have impacted adversely on access to care and on population health, not least because of awareness of what has happened in Greece [17]. So what has happened in Portugal?

\section{Methods}

We used the European Statistics on Income and Living Conditions (EU-SILC) [18] to analyse changes in self-reported unmet medical need before and after the introduction of the Troika's adjustment package. EU-SILC is an EU-wide representative population survey, the crosssectional component of which contains data on perceived unmet medical need. The unmet medical need indicator is considered a proxy for barriers experienced in access to care, consistent with other studies [17,19]. The relevant question asks respondents whether they felt unable to access medical care over the past 12 months, although he/she felt they needed it, with a supplementary question on unmet medical need. We compared data from 2010 and 2012 ( $n=21,474)$, covering the introduction of most of the austerity measures. Logistic regression models were analysed, with stratification by economic status (employed, unemployed, retired and other inactive), a for sociodemographic characteristics of the sample: age (16-80), sex (male compared to female), marital status (married compared to single) and education (post-secondary compared to secondary or below), with weighting for survey sampling design. Summary statistics presented in Table 1 show that socio-demographic characteristics of 2010 and 2012 survey samples were broadly comparable, although there were more respondents with higher education in 2012.

We also accessed and analysed multiple sources of data related to health, health care expenditure and health care utilisation from OECD, Eurostat, and the Portuguese Ministry of Health. We present key findings from available qualitative and quantitative studies, which aim to explore the impact of the recession and subsequent austerity measures on those who are most vulnerable using available survey data.

\section{Results}

\subsection{Effects of health care budget cuts on health system} and access to care

As shown in Fig. 1 and Table 2, the odds ratio (OR) of reporting unmet medical need (accounting for sociodemographic characteristics of respondents) more than doubled in the crisis year, with the greatest impact on those in employment (OR 2.82, 95\% CI 2.15-3.69), followed by the unemployed (OR 2.07, 95\% CI 1.32-3.24), and the retired (OR 2.00, 95\% CI 1.40-2.85), and other economically inactive groups (OR 1.81, 95\% CI 1.11-2.96). EU-SILC also collects the reason for not seeking care and Table 3 shows changes in the frequency of reporting of different perceived

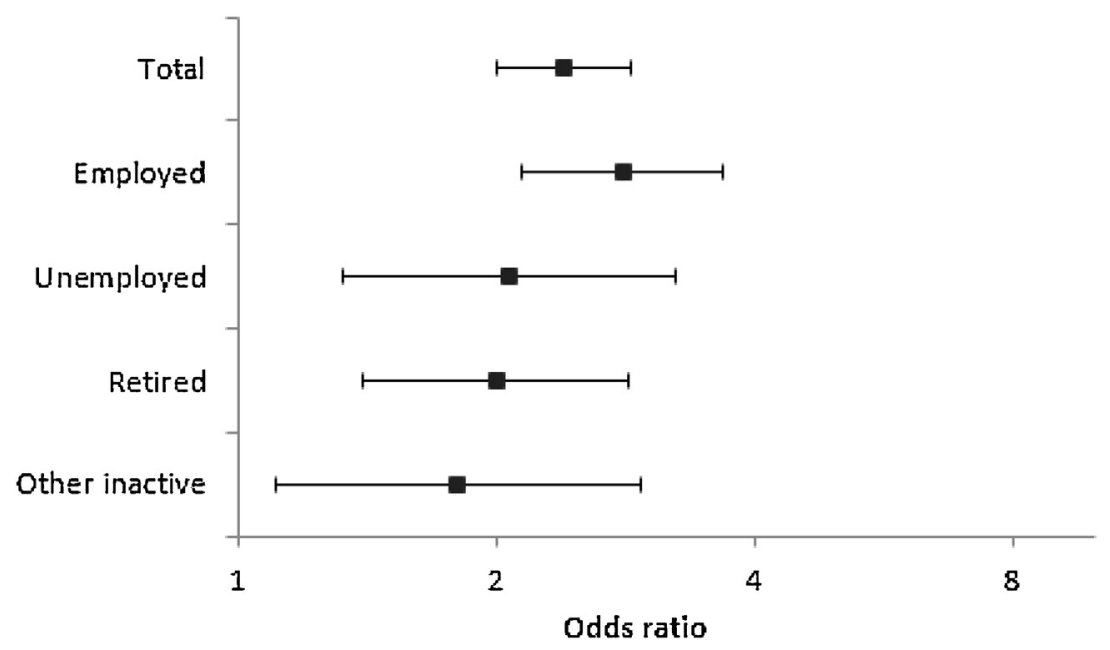

Fig. 1. Odds of reporting unmet medical need in Portugal in crisis year, by economic status of respondent. *Accounting for age, sex, family status and education. 
Table 2

Odds of reporting unmet medical need in 2010 and 2012 by economic status.

\begin{tabular}{|c|c|c|c|c|c|}
\hline & Total & Employed & Unemployed & Retired & Other inactive \\
\hline \multirow[t]{2}{*}{ Crisis year (2012) } & $2.4074^{* * *}$ & $2.8164^{* * *}$ & $2.0693^{* *}$ & $2.0013^{* * *}$ & $1.8089^{*}$ \\
\hline & {$[2.0091,2.8848]$} & {$[2.1501,3.6891]$} & {$[1.3230,3.2365]$} & {$[1.4037,2.8533]$} & {$[1.1062,2.9580]$} \\
\hline \multirow[t]{2}{*}{ Age (16-80) } & $1.0084^{* * *}$ & $1.0213^{* * *}$ & $1.0346^{* * *}$ & 0.9826 & $1.0278^{* * *}$ \\
\hline & {$[1.0042,1.0127]$} & {$[1.0109,1.0318]$} & {$[1.0166,1.0529]$} & {$[0.9633,1.0023]$} & {$[1.0175,1.0383]$} \\
\hline \multirow[t]{2}{*}{ Sex (male) } & 0.8908 & $0.7486^{*}$ & 1.0533 & 1.0996 & 1.2882 \\
\hline & {$[0.7579,1.0470]$} & {$[0.5898,0.9501]$} & {$[0.7136,1.5548]$} & {$[0.7845,1.5412]$} & {$[0.7553,2.1972]$} \\
\hline \multirow[t]{2}{*}{ Family status (married) } & 0.8733 & 0.8547 & 0.883 & $0.6081^{* *}$ & $0.5441^{*}$ \\
\hline & {$[0.7307,1.0438]$} & {$[0.6570,1.1119]$} & {$[0.5674,1.3740]$} & {$[0.4272,0.8655]$} & {$[0.3199,0.9253]$} \\
\hline \multirow[t]{2}{*}{ Education (post-secondary) } & $0.4706^{* * *}$ & $0.4880^{* * *}$ & 0.4584 & $0.2713^{*}$ & 0.7427 \\
\hline & {$[0.3393,0.6528]$} & {$[0.3276,0.7269]$} & {$[0.1811,1.1603]$} & {$[0.09215,0.7990]$} & {$[0.2462,2.2405]$} \\
\hline Pseudo $R$-squared & 0.03 & 0.04 & 0.04 & 0.03 & 0.03 \\
\hline Sample size & 21,474 & 10,328 & 2228 & 5379 & 3539 \\
\hline
\end{tabular}

Odds ratios; $95 \%$ confidence intervals in brackets.

${ }^{*} p<0.05$, weighted for sampling.

** $p<0.01$, weighted for sampling.

*** $p<0.001$, weighted for sampling.

barriers. There was an almost 70\% increase in odds of citing financial barriers (OR 1.68, 95\% CI 1.32-2.12), a more than doubling the odds of citing waiting times (OR 2.18, 95\% CI 1.20-3.98) and inability to take time off work or family responsibilities (OR $2.40,95 \%$ CI $1.40-4.12$ ), as well as a large increase in those reporting delaying care in the hope that the problem would resolve on its own (OR 13.98, 95\% CI 6.51-30.02). However, caution is needed in interpreting changes in reported reasons for unmet need due to small numbers, which in 2012 varied from 24 responders attributing unmet need due to distance/transportation problems to 384 reporting financial reasons.

At the time when perceived barriers to accessing care were rising, as described above, there has been a substantial shift on the sources of health care expenditure. The proportion of public funding decreased from $69 \%$ to $64 \%$, and, correspondingly, private expenditure increased from $31 \%$ to 36\% between 2010 and 2012. This shift was prior to the increase in user charges introduced in 2012 [5]. Out of pocket payments (OOPs) constitute around three quarters of private expenditure on healthcare in Portugal, and after a steady rise to $€ 448$ per capita prior to the crisis, they declined to $€ 408$ per capita in 2013 , although public funding declined at a faster pace.

A 2012 patient survey, which included 375 patients sought to provide a snapshot of medication adherence in patients with chronic conditions, found that $22.8 \%$ of patients did not purchase prescribed medication, with financial problems cited as one of the main reasons [20]. Another study linked pharmaceutical policy interventions such as harmonizing reimbursement levels and campaigns to promote generics, to utilisation of antipsychotic drugs, found an increase in the use of generic medicines, but also to a decrease in overall sales, consistent with reduced access to medicines [21]. Physicians also estimated that $60 \%$ patients are failing to attend follow up treatment due to financial hardship [22].

A recent ecological study analyzing the impact of user fees and transport costs increase on emergency services found that the rise in OOPs did not lead to differences in emergency visits between patients exempt and not exempt from payments in three Portuguese hospitals, however longer travel distance because of loss of nearby facilities was a significant factor in reducing emergency visits [23].

Table 3

Odds of reporting specific reasons for unmet medical need in 2010 and 2012.

\begin{tabular}{|c|c|c|c|c|c|c|}
\hline & Could not afford & Waiting list & Lack of time & Travel distance & Wait and see & Other \\
\hline \multirow[t]{2}{*}{ Crisis year (2012) } & $1.6759^{* * *}$ & $2.1819^{*}$ & $2.4037^{* *}$ & 1.9753 & $13.981^{* * * *}$ & $3.1130^{* * * *}$ \\
\hline & {$[1.3221,2.1242]$} & {$[1.1960,3.9805]$} & {$[1.4038,4.1159]$} & {$[0.6211,6.2822]$} & {$[6.5125,30.016]$} & {$[1.8612,5.2068]$} \\
\hline \multirow[t]{2}{*}{ Age (16-80) } & $1.0062^{*}$ & 1.0200 & $0.9832^{*}$ & $1.0539^{* *}$ & 1.0055 & $1.0202^{* * * *}$ \\
\hline & {$[1.0003,1.0122]$} & {$[1.0064,1.0338]$} & {$[0.9696,0.9970]$} & {$[1.0194,1.0896]$} & {$[0.9948,1.0163]$} & {$[1.0105,1.0300]$} \\
\hline \multirow[t]{2}{*}{ Sex (male) } & $0.6762^{* * *}$ & 1.143 & 0.887 & 0.3573 & 1.1422 & $1.8344^{* *}$ \\
\hline & {$[0.5379,0.8500]$} & {$[0.6809,1.9188]$} & {$[0.5484,1.4346]$} & {$[0.08732,1.4619]$} & {$[0.7575,1.7224]$} & {$[1.1794,2.8532]$} \\
\hline \multirow[t]{2}{*}{ Family status (married) } & 0.8971 & 1.3253 & 1.6218 & 0.3248 & 0.8455 & $0.5141^{* * *}$ \\
\hline & {$[0.7000,1.1497]$} & {$[0.7170,2.4498]$} & {$[0.8984,2.9277]$} & {$[0.07436,1.4188]$} & {$[0.5372,1.3307]$} & {$[0.3412,0.7746]$} \\
\hline \multirow[t]{2}{*}{ Education (post-secondary) } & $0.2342^{* * * *}$ & 0.7037 & 0.7605 & 2.0038 & 0.6165 & 0.8244 \\
\hline & {$[0.1266,0.4334]$} & {$[0.2404,2.0595]$} & {$[0.3784,1.5283]$} & {$[0.3426,11.718]$} & {$[0.2963,1.2825]$} & {$[0.4095,1.6597]$} \\
\hline Pseudo $R$-squared & 0.02 & 0.03 & 0.02 & 0.09 & 0.08 & 0.04 \\
\hline Sample size & 21,474 & 21,474 & 21,474 & 21,474 & 21,474 & 21,474 \\
\hline
\end{tabular}

Odds ratios; $95 \%$ confidence intervals in brackets.

${ }^{*} p<0.05$, weighted for sampling.

** $p<0.01$, weighted for sampling.

*** $p<0.001$, weighted for sampling. 
In 2013 an assessment of health needs was conducted in two municipalities within the Metropolitan Area of Lisbon, Amadora and Sintra, characterised by economic deprivation and the highest concentration of migrants. Among 253 users of primary health care, 176 of whom were migrants, $45.1 \%$ were unable to afford medicines. $25 \%$ of the interviewees could not afford health care when needed, and 20.6\% reported having serious difficulties paying for diagnostic tests [24]. Problems of accessing primary care were reported, with $34.4 \%$ of those interviewed reporting lacking access to a general practitioner, a figure that rose to $43.8 \%$ for foreign-born health care users [24].

Between 2011 and 2013, the Portuguese National Health Service (NHS) lost $2.3 \%$ of its workforce, including $3.2 \%$ of its nursing staff. In 20131211 Portuguese nurses registered for work in the UK, compared to 20 in 2006/2007 [25]. Although the number of NHS physicians has increased by $3.8 \%$ in the same period [26], their salaries, as well as those of other public servants, suffered cuts between 2011 and 2013, and again in the last quarter of 2014, falling by $3.5 \%$ for salaries between $€ 1500$ and $€ 2000$ and up to $10 \%$ for salaries above $€ 4165$. The ratio of nurses to physicians, which was already low, declined further between 2008 and 2012, from 1.5 to 1.4 [27]. In addition, government decree 266-D/2012 increased the working week from 35 to $40 \mathrm{~h}$, which helped to cut overtime payments by an average of about $6.1 \%$ for physicians and nurses. In a survey conducted among 3448 NHS physicians, $65 \%$ reported a shortage of medical equipment/products in their facilities and $80 \%$ reported that cuts in the NHS budget compromised care quality and access. Furthermore, 2014 and 2015 saw several hospital administration boards resign following disagreement with policy priorities or centrally-imposed cutbacks [22].

\subsection{Effects of the recession on health}

According to EUROSTAT, unemployment has risen rapidly, from $7.6 \%$ in 2008 to $14 \%$ in 2011 , reaching $17.3 \%$ in the first quarter of 2013 and decreasing to $12.3 \%$ as of the third quarter of 2015 [28]. Risk of poverty and social exclusion in the population increased from $24.4 \%$ to $27.5 \%$ between 2011 and 2013; material deprivation rose from $20.9 \%$ to $25.5 \%$; with severe material deprivation rising from $8.3 \%$ to $10.9 \%$. The poverty rate among children under 18 years of age also increased, from $28.6 \%$ in 2011 to $31.7 \%$ in 2013 [28].

Suicide rates are a contentious issue in Portugal and there is uncertainty about data prior to 2014, when a new reporting system was introduced. However, calls to Emergency Medical Services by those reporting suicidal thoughts increased by 29.3\% from 2011 to 2012 [29], but a recent report produced contradictory results [30]. One recent Portuguese study did find an association between suicide and the level of material deprivation in municipalities [31]. The reported incidence of depression also increased in Portugal from 2004 to 2012, partially due to improved identification of cases [32]. A number of studies suggest that mental health-related illness is more prevalent in Portugal than in other European countries [33-35]. Per capita consumption of anti-depressants was highest among 18 EU member states [9]. However, commentators have noted that while recession has probably worsened the situation, including a $30 \%$ rise in new consultations among children between 2011 and 2013, and a 41\% increase in the number of calls to a suicide helpline between 2011 and 2012, studies of this topic are lacking [33].

Mortality from respiratory diseases has also increased, by 16\% between 2011 and 2012, following decades of continuing decreases. 2012 also saw an increase in hospitalizations for respiratory illness, up by $9.9 \%$ since 2011 [36,37]. While excess mortality was largely attributed to the seasonal flu outbreak [38], the death rate has been abnormally high [39]. Portugal has one of the highest rates of people unable to keep their house adequately warm (28\% in 2013), only superseded by Greece in recent years [28]. The rise in respiratory diseases also coincided with restriction on exemption for co-payments, with only those patients whose disability level was $60 \%$ or above being exempt and that only after completing complicated administrative procedures that introduced delays in assessment of the level of disability [15]. Consistent with this, the National Observatory of Respiratory Disease has drawn attention to the reduced use of bronchodilators in 2012, attributed to difficulties affording medicines due to financial constraints [36].

Infectious diseases generally have remained under control. Tuberculosis incidence rates continued to fall in recent years, reaching 22 per 100,000 in 2013 [10]. Newly diagnosed HIV cases have decreased overall (from 15 per 100,000 population in 2011 and 2012 , to per 10 per 100,000 in 2013 and 11 per 100,000 in 2014) yet vertical transmission reached 0.7 in 2013 and 2014, raising from 0.5 and 0.3 in 2011 and 2012. However, HIV incidence rates are still high relative to the rest of the EU, while there are some concerns for the future as spending on HIV prevention has been reduced, including fewer syringes (mostly distributed through pharmacies) and condoms being distributed, in both cases to less than half of the amount preceding the implementation of austerity, as well as cuts to screening programmes $[40,41]$. Especially detrimental for public health has been the reduction of accessibility to migrants, as many new cases relate to this population.

Finally, there has been an increase in reported violence against health professionals in the NHS. In 2014 there were 531 notifications of violence, a $160 \%$ increase from the previous year, with larger numbers of service users reporting dissatisfaction about, for example, transport, purchase of medicines and payment of user fees $[42,43]$.

\section{Discussion}

This study shows that the recession, followed by the policy of austerity adopted in Portugal has been accompanied by a demonstrable worsening of self-reported access to health care, most marked among those who are not exempt from the increases in co-payments implemented as part of the austerity package. While an ecological study [23] looking at aggregated data did not find differences in emergency admissions between patients that were exempt or not-exempt from payments in 2012 compared to 2011, individual level data shows a contrasting picture. The 
results of the analysis of EU-SILC data are in line with those of local surveys demonstrating that many Portuguese, particularly from more deprived communities, are experiencing barriers to accessing services, including primary care $[24,38]$. This is despite the recent assessment, performed for the Ministry of Health, which showed that there has been substantial expansion of primary care in Portugal [44]. The reasons are complex but they seem to involve a combination of reductions in both demand and supply. The former seems, in part, to reflect increases in co-payments but also the difficulty that the increasing number of people that are exempt face when seeking to establish their eligibility because of the many bureaucratic obstacles involved. The exemptions seemed to have slightly cushioned the impact on access to care among the unemployed, as the largest increase in unmet need was seen among those in employment. Costs constitute a major barrier to accessing care, although long waiting times also seem important. The latter could be explained by reductions in supply, including cuts to provision of services, and the number of nurses employed [27]. This has placed additional pressure on those providing care, which can be expected to demotivate those who remain.

Although a substantial reduction in pharmaceutical expenditure in Portugal reflects generally successful implementation of policies aimed at introducing clinical guidelines, monitoring systems, compulsory electronic prescriptions and generic substitution in both the public and private sector [27], many patients with chronic conditions seem to have cut down on use of medication for financial reasons. Non-adherence to prescribed medication, including secondary prevention of myocardial infarction, due to inability to afford medicines has already led to documented cases of unplanned readmission of patients in Greece [45] and Spain [46].

Cuts to human resources, achieved mainly through salary reductions and increasing workload have been linked to emigration of health professionals. Coupled with worsening working conditions, including increasing levels of violence, the risk of an understaffed health system and demoralised workforce is clear.

This study has some limitations. First, the data on unmet need is self-reported and is subject to respondent bias. It also does not allow us to quantify the number of times the responded felt he or she had an unmet need during the specified period. Despite these limitations, this measure is widely used in studies of this type, as this is the only indicator of unmet need available across the EU countries, serving as a proxy for barriers to accessing care and the reasons thereof. Second, in the absence of sufficient peer-reviewed evaluations of service delivery and patient experience, we had to rely on official statistics, grey literature as well as preliminary results of ongoing studies. This has been a problem in several countries most affected by the crisis and severe austerity; investment in data collection and research has been among the first casualties. For example, Greece withdrew from the Survey of Health, Ageing and Retirement in Europe (SHARE) just before the financial crisis, when the data collected would have been of particular value. Third, there are some gaps in information, including change in suicide registrations, which complicate assessment of one of the most sensitive indicators of the consequences of recessions for health. These limitations notwithstanding, the study offers one of the first comprehensive pictures of changes to the Portuguese health system and the health of the population following the introduction of austerity policies as a result of the financial crisis.

The impact of austerity measures in the health sector needs to be viewed in the context of the pre-existing situation in Portugal. Both before and after the imposition of austerity self-reported health status as well as some mental health indicators in Portugal were among the worst in the EU.

Finally, the political and economic situation has been turbulent. Elections held in June 2011 forced the Socialist government from office, ushering in a coalition of the Partido Social-Democrata (centre-right) and Centro Democrático Social - Partido Popular (conservative), which oversaw the implementation of the adjustment programme until its termination in May 2014. The latest general election in October 2015 saw a centre-right minority government come into power, only to be overthrown a few weeks later following a no confidence motion headed by the Socialist party with the support of the Communist Party, the Greens and the Left Bloc, which pledged to "turn the page on austerity".

At last, the Portuguese economy is showing some signs of improvement but it is too early to know whether this will be matched by an improvement in health. Yet, even if it is, Portugal has lost several years of much needed progress in closing the health gap with the rest of Europe.

\section{Conclusions}

The available evidence points to a clear deterioration in access to health care in Portugal since austerity measures imposed by the Troika came into effect in 2011, especially for vulnerable population groups not benefiting from exemptions from charges. This situation is familiar to other countries in Southern Europe, particularly Greece [17] and Spain [47], where the universality of health coverage, population health and existence of the welfare state has been challenged by austerity measures [48].

The bailout agreement ended in May 2014. However, the OECD reported that the Portuguese government had imposed cuts double those demanded in the original bailout agreement [49]. The impact of the cuts of this scale on the fairly well functioning Portuguese NHS [50] and population health is not yet fully clear. This paper presents early evidence of the impacts of healthcare cuts and recession on access to services and health outcomes. The Portuguese government no longer needs external assistance but the results presented in this paper suggest that measures are now needed to ensure access to care across many population groups, particularly those overlooked by the exceptions, in order to mitigate the damage of the recession and the austerity.

\section{References}

[1] European Commission. Eurostat database; 2016. 
[2] IMF. World economic outlook October 2014. Legacies, clouds, uncertainties. Washington: International Monetary Fund; 2014

[3] Eurostat. Self-perceived health by sex, age and labour status; 2015 [last update: 27.03.15].

[4] Portugal Go, IMF, EC ECB. Portugal: memorandum of understanding on specific economic policy conditionality; 2011.

[5] Sakellarides C, Castelo-Branco L, Barbosa P, Azevedo H. The impact of the financial crisis on the health system and health in Portugal. Geneva: World Health Organization; 2014.

[6] OPSS. Relatório de Primavera 2012 - Crise e Saúde Um País em Sofrimento. Coimbra: Observatório Português dos Sistemas de Saúde; 2012

[7] Hespanha P, Ferreira S, Pacheco V. O Estado Social. Crise e Reformas. A anatomia da crise: identificar os problemas para construir as alternativas. Coimbra: Centro de Estudos Sociais da Universidade de Coimbra; 2013. p. 191-210.

[8] Barros PP, Machado SR, Simoes AJde. Portugal. Health system review. Health Systems in Transition 2011;13(4):1-156.

[9] OECD. Health at a glance: Europe 2014. Paris: OECD Publishing; 2014.

[10] WHO. In: Europe WROf, editor. European health for all database. Copenhagen: World Health Organization; 2015

[11] OECD. Health at a glance 2015. OECD indicators. Paris: OECD Publishing; 2015.

[12] OPSS. Relatório de Primavera 2013 - Duas Faces da Saúde. Coimbra; 2013.

[13] OPSS. Relatório de Primavera 2014 - Síndroma de Negação. Coimbra; 2014

[14] ACSS. Taxas moderadoras - atualização de dados a 1 de agosto de 2014; 2014 http://www.acss.min-saude.pt/DownloadsePublica \%C3\%A7\%C3\%B5es/TabelaseImpressos/TaxasModeradoras/ TaxasModeradorasAtualiza\%C3\%A7\%C3\%A3odedados/tabid/664/ language/pt-PT/\%20Default.aspx (accessed 31.01.2015).

[15] ERS. O Novo Regime Jurídico das Taxas Moderadoras. Porto: Entidade Reguladora da Saúde; 2013.

[16] European Commission. The economic adjustment programme for Portugal. Brussels: European Commission; 2011

[17] Kentikelenis A, Karanikolos M, Reeves A, McKee M, Stuckler D. Greece's health crisis: from austerity to denialism. Lancet 2014;383(9918):748-53.

[18] Eurostat. Cross-sectional European Union Statistics on Income and Living Conditions (EU-SILC), 2010 and 2012 users' database. Luxembourg: European Commission; 2014.

[19] Karanikolos M, Gordeev VS, Mackenbach JP, McKee M. Access to care in the Baltic States: did crisis have an impact? European Journal of Public Health 2015.

[20] da Costa FA, Pedro AR, Teixeira I, Braganca F, da Silva JA, Cabrita J. Primary non-adherence in Portugal: findings and implications. International Journal of Clinical Pharmacy 2015;37(4):626-35.

[21] Leopold C, Zhang F, Mantel-Teeuwisse AK, Vogler S, Valkova S, RossDegnan D, et al. Impact of pharmaceutical policy interventions on utilization of antipsychotic medicines in Finland and Portugal in times of economic recession: interrupted time series analyses. International Journal for Equity in Health 2014;13:53.

[22] Gomes C. Metade dos médicos dizem que doentes faltam mais às consultas devido a custos. Jornal Médico 2014

[23] Ramos P, Almeida A. The impact of an increase in user costs on the demand for emergency services: the case of Portuguese hospitals. Health Economics 2015.

[24] Hernández-Plaza S, Padilla B. Final Report Summary - PSYSPOCUC - Meeting the healthcare needs of culturally diverse populations: a psycho-sociopolitical approach to cultural competence in health professionals. In: Marie Curie Actions FP7-PEOPLE-2010-IEF (Ref. 272976), 7th Research Framework Programme. Brussels: European Commission; 2014.

[25] Lusa A. Enfermeiros portugueses no Reino Unido aumentaram 500\%. Notícias ao Minuto 2014 (04.12.14).
[26] ACSS. Balanço Social Global do Ministério da Saúde e do Serviço Nacional de Saúde (SNS). Lisboa: Administração Central do Sistema de Saúde/Ministério da Saúde; 2014.

[27] Correia T, Dussault G, Pontes C. The impact of the financial crisis on human resources for health policies in three southern-Europe countries. Health Policy (Amsterdam, Netherlands) 2015.

[28] Eurostat. Statistics database. European Commission; 2015.

[29] Madeira M. Tentativas de suicídio aumentam com a crise. Público 2013, 07 01.13.

[30] WHO. Preventing suicide: a global imperative. Geneva: World Health Organization; 2014.

[31] Santana P, Costa C, Cardoso G, Loureiro A, Ferrao J. Suicide in Portugal: spatial determinants in a context of economic crisis. Health \& Place 2015;35:85-94.

[32] DGS. Portugal. Saúde Mental em números - 2014. Lisboa: DirecçãoGeral da Saúde, Ministério da Saúde; 2014

[33] Augusto GF. Mental health in Portugal in times of austerity. Lancet Psychiatry 2014;1(2):109-10.

[34] Almeida JMCd, Xavier M. Estudo Epidemiológico Nacional de Saúde Mental - 1 Relatório. Lisboa: Faculdade de Ciências Médicas, Universidade Nova de Lisboa; 2013.

[35] Gusmão R, Xavier M, Heitor MJ, Bento A, de Almeida JMC. Depressive disorder burden: global epidemiological issues and information needs in Portugal. Acta Médica Portuguesa 2005;18(2):129-46.

[36] ONDR. Prevenir a Doença Acompanhar e Reabilitar o Doente. Lisboa; 2013.

[37] DGS. Portugal. Doenças Respiratórias em números - 2014. Lisboa: Direcção-Geral da Saúde. Ministério da Saúde; 2014.

[38] Mazik A, Gergonne B, Nielsen J, Wuillaume F, Vistanen J, Fouillet A. Excess mortality among the elderly in 12 European countries, February and March 2012. Eurosurveillance 2012;17(14).

[39] Nunes B. Building a mortality baseline to monitor and estimate excess mortality associated with influenza epidemics and other events in Portugal. ECDC; 2012.

[40] DGS. Portugal. Infeção VIH SIDA e Tuberculose em números - 2013. Lisboa: Direcção-Geral da Saúde, Ministério da Saúde; 2013.

[41] DGS. Portugal. Infeção VIH, SIDA e Tuberculose em números - 2015. Lisboa: Direcção-Geral da Saúde, Ministério da Saúde; 2015.

[42] DGS. Natalidade, Mortalidade Infantil, Fetal e Perinatal 2009/2013. Lisboa: Direcção-Geral de Saúde, Ministério da Saúde; 2014.

[43] Lusa A. Violência contra profissionais de saúde mais que duplicou em 2014. Público 2015, 24.02.15.

[44] Pita Barros P, Lourenço A, Moura A, Correia F, Silvério F, Gomes JP. Políticas Públicas em Saúde: 2011-2014 Avaliação do Impacto. Portugal: Nova Healthcare Initiative - Research/Universidade Nova de Lisboa; 2015

[45] Davlouros P, Gizas V, Stavrou K, Raptis G, Alexopoulos D. DES thrombosis related to antiplatelet therapy noncompliance: a consequence of the Greek financial crisis. International Journal of Cardiology 2013;168(4):4497-9.

[46] Dominguez-Rodriguez A, Mendez-Vargas C, Sanchez-Grande A, Avanzas P, Abreu-Gonzalez P. [Healthcare administration and the economic crisis: apropos of a case]. Gaceta Sanitaria/SESPAS 2014;28(4):342-3.

[47] Legido-Quigley H, Montgomery CM, Khan P, Atun R, Fakoya A, Getahun $\mathrm{H}$, et al. Integrating tuberculosis and HIV services in low- and middle-income countries: a systematic review. Tropical Medicine \& International Health: TM\&IH 2013;18(2):199-211.

[48] Kentikelenis A. Bailouts, austerity and the erosion of health coverage in Southern Europe and Ireland. European Journal of Public Health 2015;25(3):365-6.

[49] Morgan D, Astolfi R. Health spending growth at zero: which countries, which sectors are most affected? Paris: OECD Publishing; 2013.

[50] OECD. OECD reviews of health care quality: Portugal 2015. OECD; 2015 . 